\title{
Challenges to remote emergency decision-making for disasters or Homeland Security
}

\author{
Colin Mackenzie · Peter Fu-Ming Hu · Carsten Fausboll · Michael Nerlich • \\ Thomas Benner · David Gagliano · Warren Whitlock · David Lam · \\ Yan Xiao
}

Received: 1 October 2005/ Accepted: 1 October 2006/Published online: 10 January 2007

(C) Springer-Verlag London Limited 2006

\begin{abstract}
New technology allows information gathering and collaboration across information networks that would be of benefit to emergency response. In a Homeland Security Exercise we compared the utility of fixed and mobile video and high quality still images on remote expert decision-making. Sixteen experts situated in three countries viewed and seven evaluated events of the exercise assisted by audio commentary of local knowledge experts. They evaluated the usefulness of black and white $(\mathrm{B} / \mathrm{W})$ compared to color images, fixed fast video versus slow video and still images. Technical difficulties interrupted image transmission to one remote site for half the Exercise. However, the images were found useful, color more so than $\mathrm{B} / \mathrm{W}$, mobile more so than fixed. The combination of still images and video was best. Playback of recorded
\end{abstract}

\footnotetext{
C. Mackenzie ( $\varangle)$ · P. F.-M. Hu · D. Lam ·

Y. Xiao

University of Maryland, 701W. Pratt Street, 5th Floor,

Baltimore, MD 21201, USA

e-mail: cmack003@umaryland.edu

C. Fausboll

NATO, Brussels, Belgium

M. Nerlich · T. Benner

University of Regensburg, Regensburg, Germany

D. Gagliano

Northrop Grumman Corporation, Reston, VA, USA

W. Whitlock

Fort Gordon, GA, USA

D. Lam

Telemedicine and Advanced Technology Research Center, United States Army, Fort Detrick, MD, USA
}

images was especially useful for remote evaluation and decision-making. Improved reliability for these imaging technologies could improve shared awareness and large-scale coordination for Homeland Security events.

Keywords Remote decision-making - Homeland security · Emergency response · Video · Large-scale collaboration - Computer supported cooperative work

\section{Introduction}

Computer supported cooperative work (CSCW) technologies offer a range of methods to enable teams to communicate, share work spaces, exchange ideas, plan, calibrate their situation assessment and work in parallel with great efficiency (Olson et al. 1999). In the context of large-scale collaboration, especially when tasks are driven by external events, the strengths and limitations of such CSCW technologies are incompletely understood and this lack of understanding will impact both their future uses and the expectations from implementation. Potentially the ability for remote experts to share relevant parts of their expertise "just-in-time" or for remote experts to provide on-site decision-makers with suggestions to build on ideas or courses of action is attractive. For Emergency Management Responders planning for rare scenarios, such use of real or virtual expert input could allow significant reductions in time to build, review, revise and rereview those plans. Furthermore, real-time responses for such Emergency Management Responders may benefit from both on-site and remote experts to suspect and confirm the presence of confusing factors or uncertainties dynamically as the scenario unfolds, so 
that situational assessment can be shared and jointly developed. The technology to facilitate such remote collaboration among distributed members includes, voice, data and images, both video and still. The Internet has facilitated inexpensive communications of these media and the computers, recorders and cameras have recently become less expensive, more robust and refined. The technology now has improved performance (e.g., mobile and portable communication). However, there are trade-offs in quality and frequency of image transmission that could impact the decisionmaking and situational awareness among distributed collaborators (Wootton et al. 1997; Chapanis et al. 1972; Xiao et al. 1999). There are also challenges for expert decision-making when Emergency Management or Disaster Response recommendations need to be coordinated dynamically with on-site responders from a geographically foreign location.

Disaster response for natural or man-made emergencies requires disparate expertise from multiple widespread forms (e.g., personnel, resources, databases). On-site responders can benefit from remotely situated experts who share the key aspects of their expertise at the point in the proceedings that these aspects are relevant. Such distributed decision-making can provide time-critical information that may be lifesaving or protect rescuers or victims from exposure to hazards, and can prevent fixations or failures to consider earlier discarded hypotheses. The remote experts can function almost like a "transactive" memory for the on-site Emergency Management Responders who may be too busy with multiple tasks and rapidly changing events to be able to access databases or to accurately recall past information or communications (Wegner et al. 1991, Xiao et al. 2002). This study proposed to address several of the limitations from prior studies by including: real-time local knowledge audio supplements from on-site, a team of remote emergency management experts to counteract the varying background and expertise of individual remote experts, training pre-event to enhance coordination, the same low bandwidth black and white $(\mathrm{B} / \mathrm{W})$ video enhanced with high bandwidth color video and still images transmitted to all facilities to minimize diagnostic biases and differences in decision-making from different remote locations.

We examined evidence to support three hypotheses of relevance to Homeland Security or Disaster Response during an exercise at the University of Maryland, Baltimore Campus: (1) remote experts can identify real-time emergency events by viewing mobile, slow color video [1-2 frames/s (fps)] and the currently used fixed $\mathrm{B} / \mathrm{W}$ public safety video surveillance camera
(20 fps) images of events; (2) high quality still images sent to remote experts convey details not recognized in video; (3) still color images promote situational awareness in geographically foreign locations.

We also assessed obstacles and challenges in coordination across organizational boundaries and routine information technology networks using subjective utility judged by remote experts. The Homeland Security Exercise had the objective to improve emergency response coordination and called for responses from a collection of organizations (North Atlantic Treaty Organization (NATO) civil defense, European and United States (US) Emergency Management Responders, Police, Physicians, University Public Safety personnel and both State and Federal Agencies), who under normal circumstances, did not work together. We expect that such modes of collaboration would be prevalent in responses to world-wide disasters and other high consequence events.

\section{Methods}

The University of Maryland (UM) Homeland Security Exercise was viewed and evaluated remotely by experts in emergency operation centers (EOC) in Regensburg, Germany; Brussels, Belgium; and Baltimore, US. These EOC were connected with three integrated digital services network (ISDN) lines routed through Fort Gordon, Georgia, US. One ISDN line each to UM, UR, and NATO with two cameras C1, the Public Safety surveillance B/W camera and C2, a mobile wireless camera. A secure web server and video-cassette recorder (VCR) allowed duplex video-teleconference (VTC) communications and recording of the ISDN connections. Locations (L) in UM, UR, and NATO for video communication of the Exercise through three real-time video ISDNs are shown in Fig. 1.

\subsection{Exercise scenario}

A "Dirty Bomb" (a real radiation source in a black briefcase) activated radiation sensors in a kiosk on the UM Campus outside the hospital (Fig. 2 shows the kiosk with the briefcase). The sensors automatically dialed a telephone alert to the Environmental Health and Safety Offices, which sent a team to examine the alarming sensor and both confirmed radiation and activated the emergency response process. The bomber contacted a local television station to tell them about both the Dirty Bomb and a second conventional bomb set to explode in $45 \mathrm{~min}$ in the Emergency Medical 
Fig. 1 Connections with emergency operations centers during exercise

Fig. 2 Comparison of bandwidth effects of video and still imagery

Fig. 3 Images from exercise show field and telecommunication events
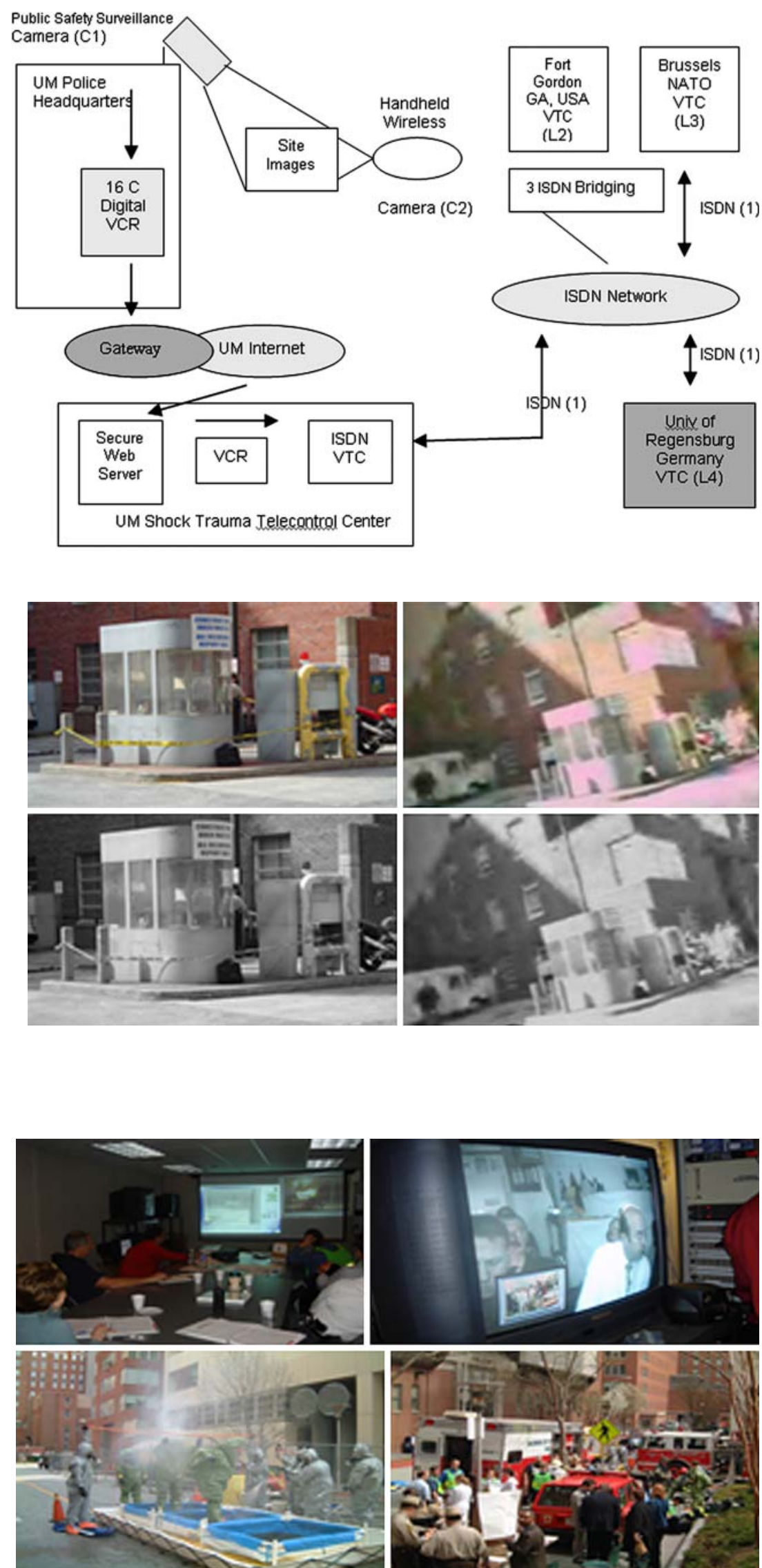


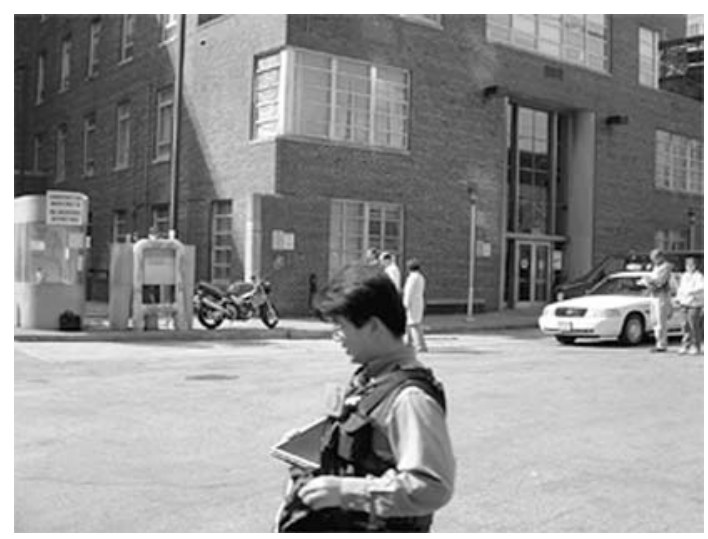

Fig. 4 Mobile wireless imaging system

Services (EMS) headquarters building. The exercise involved seven Local (UM and City), seven State and seven Federal agencies [Fig. 3. Panels show from top left, proceeding clockwise (a) EOC at UM, showing display of $\mathrm{B} / \mathrm{W}$ image from surveillance camera and color images from slow mobile video, (b) EOC in Regensburg, Germany in real-time video conference with on-site experts during the exercise, (c) Baltimore City Fire Department Response, (d) decontamination]. Remote Expert Emergency Management Responders were situated at University of Regensburg, Germany (UR, $n=9$ ) and NATO headquarters (Civil Emergency Planning Directorate), Brussels, Belgium (NATO, $n=3)$ and UM EOC $(n=4)$. Testing of the ISDN connections occurred between UM-UR and UMNATO through Fort Gordon in the week before the Exercise. However the UM-Fort Gordon-NATO-UR 4-way link could not be tested due to scheduling conflicts. The general purpose (but not details of the simulated event) of the Homeland Security Exercise was distributed by e-mail to all participants in the EOC's 2 days before the exercise. During the actual live video transmission of exercise activities, background audio information (only when requested) was provided and questions were answered by two on-site (UM) experts who were viewing the same images as were transmitted to the EOC's. Evaluations were completed or partially completed by 7 ( 3 at UR and UM, 1 at NATO) of the 16 remote EOC experts. Images for remote EOC evaluation included (a) mobile slow color video taken from a lapel-mounted camera carried by study participant who followed events on foot (Fig. 4 mobile imaging system covered both bomb sites, worked well inside buildings/ elevators, etc.), (b) B/W surveillance camera images from a fixed location, providing a view of where the "Dirty Bomb" was planted and the radiation sensors were triggered. Evaluation forms (Table 1) were completed serially at specific times (shown at end of Table 1) identified on the master event synchronization list (MESL) for the exercise. Still, high quality (3.0 megapixel) images of the Exercise taken with a digital camera by a second study participant were evaluated.

\subsection{Data collection}

In Table 1: 10 statement evaluation completed serially, in real-time, during the exercise identifying decisions made, uncertainty, activities occurring, problems identified, priorities, information needed, outcomes and comments; Table 2: 20 question form completed 1 month after the participants had viewed video images and made remote assessments of the Homeland Security Exercise; Table 3: the exercise Evaluation Questionnaire Kit included 19 statements in relation to the telecommunications, completed at the end of the exercise, on use of video in decision-making and use of images for remote EOC; Table 4: post-evaluation questions including strengths, weaknesses, opportunities, threats (SWOT) analysis revealed by the exercise. All statements were scored on a Likert scale of $1=$ strongly disagree to $5=$ strongly agree. Qualitative data were requested by including free comments sections.

\section{Results}

\subsection{Technical and interoperability issues}

Transmission gaps occurred due to the service provider's interoperability problems that interrupted image transmission to NATO for $1.5 \mathrm{~h}$ of the $3 \mathrm{~h}$ exercise. In addition during attempted simultaneous connection to NATO and UR, audio linked with the ISDN was lost, and a land-line connection was required to maintain audio communication with UR.

\subsection{Remote decision-making (Table 1)}

University of Regensburg and NATO identified on-site decisions including detection and recognition of "Dirty Bomb", bomb location, EMS building evacuation, bomb squad defusing, emergency team activities, evacuation, shielding, readiness for casualties, incident command (IC) set-up. Unclear issues were why the hospital was not evacuated. Problems were noted in the limited perimeter cordoned off around the bomb and the proximity of the IC Post to the bomb site (both 
Table 1 Remote observation LAD demo, 26 March 2004

Answer sheet number $1,2,3,4,5,6,7,8,9,10,11,12$

Time completed

\begin{tabular}{|c|c|c|}
\hline -- hours & ---- $\min$ & \\
\hline$\square$ Medical & $\square$ Police & $\square$ Fire department \\
\hline$\square$ Military & $\square$ Civil defence & $\square$ Other \\
\hline
\end{tabular}

(Check)

1. I would predict this event will be physically affecting a population of

Circle: $<5 \quad 6-10 \quad 11-30 \quad 34-100 \quad 101-500 \quad>500$

2. List the most recent decisions made by those seen on the images displayed. (List up to three most important decisions, in order of decreasing importance.)

3. At the moment, the following is unclear to me (List up to three most important, specific areas in the order of decreasing important.)

4. How I would describe the Emergency Team Activities. (List up to three most important, descriptors, in order of decreasing important.)

5. I anticipate the following immediate problems (List up to three most important, specific problems, in order of decreasing important.)

6. List in priority the three current most important objectives of the Emergency Management Team. List your instructions to achieve objectives

7. List in priority three most important pieces of information you would like to obtain and why

8. Circle your response to the following statements

I am comfortable giving instructions to the team

\begin{tabular}{lllll}
\multicolumn{2}{c}{ Disagree } & \multicolumn{2}{c}{ Agree } \\
1 & 2 & 3 & 4 & 5 \\
1 & 2 & 3 & 4 & 5 \\
1 & 2 & 3 & 4 & 5
\end{tabular}

Given the opportunity, I would obtain more information

I know the tasks being carried out by the team

9. Circle your probability estimate of a major clean-up

10. Other comments

Lowest Highest

$\begin{array}{lllll}1 & 2 & 3 & 4 & 5\end{array}$

Points where answer sheets 1-12 to be completed

(1) Radiation sensor alarms

(2) Video surveillance camera review

(3) Significant source of radiation in abandoned briefcase found

(4) 911 called

(5) Police securing 300-foot perimeter

(6) Mini disaster ED \& STC fly-by

(7) Evacuate versus shelter in place

(8) News media conveys two bomb messages

(9) Knowledge that MIEMSS bomb set to explode at 11:45 am

(10) MIEMSS evacuation

(11) Syscon relocates

(12) Order to set up decon facility

(13) Bomb squad defuses dirty bomb

the lack of hospital evacuation and exercise perimeter were limitations intended to minimize the impact on the hospital clinical operations). These results support the hypothesis 1 that remote experts can identify realtime emergency events.
3.3 Evaluation of still image and video usefulness (Table 2)

Mean scores for disaster management 4.7 ; incident commander 3.8; trauma patient extrication 4.3 ; slow 
Table 2 Comparison of still images with live slow video transmissions

I. The images (like those shown in the LAD Demo) would be useful for:

Please circle the appropriate number 1-5 (where $1=$ strongly disagrees, $5=$ strongly agrees) for your response to the questions below.

1. Disasters where a knowledgeable person provided audio commentary

2. Incident commander for emergency response coordination in Terrorist threat agent release in local area

3. Trauma patient extrication guidance to pre-hospital personnel

4. The surveillance camera $(\mathrm{B} / \mathrm{W})$ video was useful

5. The mobile slow video image review capability was best

II. The still images of the LAD Demo (http://www.nsc.umaryland.edu):

1. Provide me with additional information not noted during slow video

2. Clarity of the still images increased my understanding of slow video events

3. The combination of still images and slow video would be best

4. The size of the thumb-nail images on the website is ok

5. I would prefer all the images to be larger

6. I would like to be able to click on and enlarge selected images

7. Images in color conveyed more than black and white $(\mathrm{B} / \mathrm{W})$

Table 3 Evaluation Question Kit. Please circle the number that corresponds to your agreement to the following statements $(1=$ strongly disagree, 5 = strongly agree $)$

\begin{tabular}{|c|c|c|c|c|c|c|}
\hline & $\begin{array}{l}1 \\
\text { Strongly } \\
\text { disagree } \\
\text { Number }\end{array}$ & $\begin{array}{l}2 \\
\text { Disagree } \\
\text { f answers }\end{array}$ & $\begin{array}{l}3 \\
\text { Don't agree } \\
\text { or disagree }\end{array}$ & $\begin{array}{l}4 \\
\text { Agree }\end{array}$ & $\begin{array}{l}5 \\
\text { Strongly } \\
\text { Agree }\end{array}$ & $\begin{array}{l}\text { No } \\
\text { answer }\end{array}$ \\
\hline $\begin{array}{l}\text { 1. I was able to make decisions based on remote visual information that were } \\
\text { not possible using verbal information alone }\end{array}$ & & & 2 & 2 & 3 & \\
\hline 2. I was better informed because of remote visual information & & & 2 & 4 & 1 & \\
\hline 3. The remote visual information changed my decision-making & & & 2 & 3 & 2 & \\
\hline $\begin{array}{l}\text { 4. The remote visual information increased the confidence I have in my } \\
\text { decisions }\end{array}$ & & & 1 & 3 & 2 & 1 \\
\hline $\begin{array}{l}\text { 5. In comparison with that of those physically present at the scene, I was able } \\
\text { to gather the same information that they did }\end{array}$ & 2 & 2 & 3 & & & \\
\hline $\begin{array}{l}\text { 6. The remote visual information provides me with useful additional } \\
\text { information }\end{array}$ & & & 1 & 3 & 3 & \\
\hline 7. I was as informed as those physically present at the scene & 2 & 1 & 3 & 1 & & \\
\hline $\begin{array}{l}\text { 8. Access to remote visual information greatly improved my ability in } \\
\text { (a) Preparation }\end{array}$ & & & & & & \\
\hline $\begin{array}{l}\text { (a) Preparation } \\
\text { (b) Guiding field emergency procedures }\end{array}$ & 1 & 1 & 2 & $\begin{array}{l}2 \\
3\end{array}$ & 1 & $\begin{array}{l}1 \\
3\end{array}$ \\
\hline (c) Coordination & & 1 & & 3 & 1 & 3 \\
\hline 9. The views provided met my needs & 1 & 2 & & 4 & & \\
\hline $\begin{array}{l}\text { 10. The transmission of the video images poses intrusion to terrorist victims' } \\
\text { privacy }\end{array}$ & 3 & 2 & & & 2 & \\
\hline $\begin{array}{l}\text { 11. The transmission of the video images of EMS activities poses an intrusion } \\
\text { in my privacy }\end{array}$ & 3 & 2 & 1 & & 1 & \\
\hline $\begin{array}{l}\text { 12. I am uncomfortable having my performance available to an off-site } \\
\text { observer }\end{array}$ & & 4 & & 3 & & \\
\hline $\begin{array}{l}\text { 13. Operation of a telemedicine system distracts the crew's attention to such } \\
\text { a degree that the safety is compromised }\end{array}$ & 1 & 2 & 4 & & & \\
\hline $\begin{array}{l}\text { 14. Operation of a telemedicine system delays regular essential steps in } \\
\text { emergency/disaster management }\end{array}$ & 1 & 3 & 1 & 1 & 1 & \\
\hline $\begin{array}{l}\text { 15. The terrorist victim would feel comfortable with the presence of a } \\
\text { telemedicine system }\end{array}$ & & 2 & 3 & 1 & 1 & \\
\hline $\begin{array}{l}\text { 16. Acquiring and transmitting video images lengthens the emergency } \\
\text { management time }\end{array}$ & & 1 & 3 & 1 & 2 & \\
\hline $\begin{array}{l}\text { 17. Using a telemedicine system poses an additional workload on the } \\
\text { emergency care providers }\end{array}$ & & & 2 & 4 & 1 & \\
\hline $\begin{array}{l}\text { 18. Transmissions of the video images provide remote decision-makers } \\
\text { information that is otherwise impossible for me to convey yet critical for } \\
\text { their decision-making }\end{array}$ & & 1 & & 3 & 3 & \\
\hline $\begin{array}{l}\text { 19. Availability of video images to off-site observers would enable me to } \\
\text { communicate better and easier }\end{array}$ & & & 1 & 6 & & \\
\hline
\end{tabular}


Table 4 Post evaluation of remote observation LAD demonstration exercise. Please circle the appropriate number 1-5 for your response to the questions below

\begin{tabular}{llllll}
1 & 2 & 3 & 4 & 5 & No \\
$\begin{array}{l}\text { Strongly } \\
\text { disagree }\end{array}$ & Disagree & $\begin{array}{l}\text { Do not agree } \\
\text { or disagree }\end{array}$ & Agree & $\begin{array}{l}\text { Strongly } \\
\text { Agree }\end{array}$ & $\begin{array}{l}\text { answer } \\
\text { Number of answers }\end{array}$ \\
\hline
\end{tabular}

1. The demonstration seen by telemedicine was realistic

2. The Exercise helped me prepare for a similar real event

3. The Campus/City emergency coordination was increased by the Exercise

4. For me, the Exercise revealed the following about the emergency management plan (EMP)

(a) Increase my knowledge of the University of Maryland (UM) campus EMP

(b) Ease of inter-campus communications

(c) Importance of coordination of campus EMP with outside agencies

(d) Need for early involvement of city in campus EMP

(e) Confidence in my decision about how to manage a similar scenario

(f) Identified how I can help the UM campus EMP

(g) Improved my understanding of how events change rapidly

(h) Showed me the need for media communication strategy

(i) Revealed a requirement for a single spokesperson

(j) Importance of control of the "Walking Worried"

(k) Showed an integrated response between Campus/City/State emergency responders

(1) Maximum use of campus resources

2

(1)

4
1

4
1

2

3
3

(1)

$3 \quad 1$

1

1

$\begin{array}{cccc} & 5 & 1 & 1 \\ 2 & 4 & & 1 \\ & 5 & 1 & 1 \\ 1 & & & 2 \\ 1 & 4 & & 1\end{array}$

3

$\begin{array}{llll} & 5 & 2 & \\ 1 & 5 & 2 & \\ 2 & 2 & 3 & 1 \\ & 2 & 3 & \\ & & 2 & 3\end{array}$

1

4

List strengths, weaknesses, opportunities and threats (three each) of using telemedicine for the emergency response demonstration exercise

color video better than fixed $\mathrm{B} / \mathrm{W}$ video 4.2 ; still images identified information missed on video 4.7 ; clarity of still images increased understanding of video events 4.4; combination of video and still images best 4.8 . The latter four scores support hypotheses 2 and 3, that high quality color images promote situational awareness and convey details not recognized in video. Image size: $6 \times 5 \mathrm{~cm}$ images compared to $23 \times 29 \mathrm{~cm}$, small images OK 4.8; larger image necessary 1.4. While the larger bandwidth of color video scored highly over B/W video, a still high quality color image of low bandwidth appeared useful for remote decision-makers to provide context for their questions and clarify uncertainties (e.g., see Fig. 2, still 3.0 megapixel image (upper left panel) and frame from slow video image (upper right panel) of the radiation source in the black briefcase, alongside the kiosk housing the radiation sensor; lower left and right panels-the same images in $\mathrm{B} / \mathrm{W}$ ).

\subsection{Value of video for decision-making} and situational awareness (Table 3)

\subsubsection{Image comparison}

Technical issues included: $\mathrm{B} / \mathrm{W}$ images from public safety surveillance cameras were inadequate as their field of view was degraded by sunlight/darkness and limited by being at a fixed location. The mobile imaging platform was able to record details of both bombs and gave greater and more flexible incident coverage, less affected by changing lighting conditions.

\subsubsection{Specific issues}

The following organizational issues were recognized: potential for international and wide area distribution links for command and control; different culture and tactics for emergency response; significant language barriers. It was noted that insider knowledge from onsite commentary and local background material and overview maps are essential for remote decision-maker understanding.

\subsection{Post evaluation comments and answers}

The results shown in Table 4 can be summarized as indicating that the remote experts saw the importance of coordination of UM with outside agencies and were able to appreciate how rapidly events changed, the need for a communication strategy, crowd control and an integrated emergency response. Highlights of the SWOT analysis shown in Table 5 included: benefit of duplex 
Table 5 Remote observation LAD exercise

Post evaluation strengths, weaknesses, opportunities and threats analysis of remote observation LAD exercise

List three strengths of using telemedicine for the demonstration exercise:

1. Images/video combined with audio/text makes understanding of incident much better

2. Different tactics of rescue people on site versus our tactics (e.g., missing marked barriers of Hot Zone)

3. Knowledge of such an event increases

4. See the difference between your and our procedure

5. Evaluate from around the world

6. Able to get some real time photos

7. Better understanding

8. Visual cues to response patterns

9. Increase participation and thereby information sharing

10. Transmission out of areas which are blocked for rescue workers

11. Supplement to spoken situation reports

List three weaknesses of using telemedicine for the demonstration exercise:

1. There should be changing speakers depending on the specialty (police, fire department EMS, etc.), also information from incident commander/on-site commander necessary

2. Live images are meaningful, recorded images important for review

3. Broadcast was not very good

4. Improve picture quality

5. Technical difficulties

6. Unclear pictures

7. Cannot cover the whole incident area

8. No communication with sector commanders

What opportunities did you see for an improved use of telemedicine in emergency response?

1. Real-time interpreter should be involved to make real-time decisions

2. Papers about the exercise/incident should be in German because the basic "school English" is long ago

3. We need improved techniques and before the happening a better "programme" and a better description of who is taking part in

4. Picture quality

5. Evaluation from around the world

6. Distribute information to a wider audience to include city/state/county EMS/systems

7. Depending on size of incident increased number of transmission capabilities

What threats did you see to using telemedicine to coordinate emergency response?

1. Audio/video transmission can provide facts about an incident which is geographically limited; but with two incident sites the images are no more that up-to-date to provide real-time decisions

2. "I do not think that there are huge risks"

3. All disasters/catastrophes

4. Policy "on-site command" cannot be replaced by telemedicine

5. Telemedicine depends on weather and light (night). Preparation time for telemedicine not known

audio communication with field mobile camera; need for communication with an on-site command and control; remote control of fixed camera; helicopter (aerial) overview image would be helpful; infrared camera capability would be needed for night use; commentary from different domain experts would be useful (e.g., police, fire, EMS, medical). Translation into native language (this occurred briefly to UR) improved understanding of emergency events and generated multiple questions from other members of the remote EOC in UR in comparison to those who had asked the earlier questions. Remote control/zoom/tilt/pan of cameras would be useful. It was difficult to distinguish between exercise responders and observer/evaluators. Problems in data and workflow in international collaboration were shown, but it is important to share information about different strategies and response tactics. Telecommunications are needed and must be improved.

\section{Discussion}

The need to provide remote and just-in-time expertise is ubiquitous in many domains, but in Emergency Management Response it could save many lives. Following the Sarin attack in the Tokyo subway in 1996, emergency responders initially believed a bomb had exploded (Okumura et al. 1998), but an emergency physician seeing the news video clips of choking and tearing victims made the clinical diagnosis remotely and called Tokyo authorities. The issue of how information gathering from multimedia is impacted by bandwidth was a question addressed by the design of the Homeland Security Exercise reported here. However, the full answer to such a question was not obtained, due to many limitations including the small sample size of remote experts completing evaluations, the communication breakdown with NATO, 
the hindsight bias in completing the evaluation of the still image usefulness after the end of the exercise and the incomplete answers to some evaluation questions that could not be filled in because the dynamic events of the exercise prevented such timely actions by evaluators. The findings although not immune to such biases and technical limitations do appear have a face validity in representing what strengths and limitations might be present in deciding bandwidth requirements in a real Emergency Management Response situation, in which remote experts were part of the distributed response team. Where bandwidth needs to be conserved, $6 \times 5 \mathrm{~cm}$ still 3.0 megapixel color images appear to have merit in conveying information and allowing remote experts to see details not appreciated in video. Mobile slow (1-2 fps) color video has less bandwidth and more flexibility in coverage over fixed location $20 \mathrm{fps} \mathrm{B} / \mathrm{W}$ video. New information technologies provide the impetus to explore alternative operating procedures and command structures (Rasmussen et al. 1991), especially when chemical, biologic or radiation threats can make physical presence hazardous.

Several important conclusions can be drawn from this preliminary study examining technology impact on remote decision-making in emergencies, all of which support our original hypotheses.

1. Intermittent high quality still images can augment understanding and information extraction from slow low bandwidth color and fast $\mathrm{B} / \mathrm{W}$ video for remote EOC. For example, in Fig. 2 the red motorbike is easily recognized in the still image and could be used as a reference point for the remote decision-makers to provide the context of their comments. In the $\mathrm{B} / \mathrm{W}$ images the motorbike is difficult to distinguish from the background, and in a frame from the low bandwidth (and low quality) color video image (right panel Fig. 2) it is difficult to be certain that the red object is a motorbike. In many circumstances public safety surveillance cameras may have dual use as shown in this demonstration. Including such existing infrastructure into emergency management response could be a cost effective way to monitor potential targets of terrorist activities. It is concluded that color not $\mathrm{B} /$ W cameras, whose field of view and contrast can be remotely controlled in varying light conditions, should be used.

2. The increased number of questions from a greater number of the remote audience at UR when German was spoken, suggests that the conveyance by on-site experts of local knowledge and clarifi- cation of remote decision-making interpretation is increased by use of native language of the remote experts.

3. Face-to-face meetings with UR, but not NATO, which occurred before the exercise improved collaboration and communications during the exercise. The prior socialization resulted in higher quality, more complete and greater number of free comments completed in the evaluations received from UR. However, there were significant technological problems with the connection to NATO and the NATO experts were clearly frustrated by the long duration gap in communication which left them unable to follow many of the events of the Exercise.

4. One feature that salvaged the lack of information during the NATO communication break was the ability to playback the previously recorded images from the mobile slow video acquisition. This playback had significant application in allowing the three members of the NATO EOC to develop awareness of what had transpired during the time interval when communications were interrupted. In addition the playback allowed all remote observers to identify events surrounding the "Dirty Bomber" planting a real radioactive source that triggered a radiation sensor. The timing of the triggered alarm was precisely known and time-coded video data enabled this video segment to be precisely located and reviewed.

5. Local domain expertise and duplex communication with the incident commander would improve remote expert decision-making. In dangerous environments (chemical, biologic, radiation, explosive) remote monitoring with video could be very helpful to safe entry and activities of EMS personnel and in coordination of the emergency management plan and health care facility readiness. Interfaces with sensors (e.g., the robot radiation detector and analyzer used in this exercise) would allow remote experts to interpret the sensor data in real-time, so expediting the appropriate emergency response.

There is a future potential, when reliability is improved, for the imaging technologies to improve shared awareness and remote distributed team collaboration. Mobile wireless color images with duplex audio and interfaces with peripheral devices used in the field would enhance the coordination of expert decisionmakers as part of a distributed team. Embedded technology in the video camera (e.g., Global Positioning System with coordinates linked to Google world display) would allow mapping and other situa- 
tional awareness artifacts to facilitate remote decisionmaking. The findings from this preliminary study have profound implications for the development and design of information and communication technologies necessary for large-scale collaboration for local and international disasters and emergency response.

Acknowledgment Supported by the Telemedicine and Advanced Technology Research Center, Ft. Detrick, Maryland, grant DAMD-17-03-01-0159. The collaboration of Fort Gordon, NATO and University of Regensburg and Northrop Grumman Corporation and the multiple State, Federal, University of Maryland and Baltimore City agencies and personnel is appreciated.

\section{References}

Chapanis A, Ochsman RB, Parrish RN, Weeks GD (1972) Studies in interactive communication: I. The effects of four communication modes on the behavior of teams during cooperative problem-solving. Hum Factors 14:487-509
Okumura T, Suzuki K, Fukuda A, Kohama A, Takasu N, Ishimatsu S, Hinohara S (1998) The Tokyo subway sarin attack: disaster management, part 2: hospital response. Acad Emerg Med 5:618-624

Olson JS, Olson GM (1999) Compurt supported cooperative work. In: Durso FT (ed) Handbook of applied cognition. Wiley, Chichester, pp 409-442

Rasmussen J, Brehmer B, Leplat J (1991) Distributed decision making: cognitive models for cooperative work. Wiley, Chichester

Wegner DM, Erber R, Raymond P (1991) Transactive memory in close relationships. J Pers Soc Psychol 61:923-929

Wootton R, Dornan J, Fisk NM, Harper A, Barry-Kinsella C, Kyle $P$ et al (1997) The effect of transmission bandwidth on diagnostic accuracy in remote fetal ultrasound scanning. $\mathbf{J}$ Telemed Telecare 3:209-214

Xiao Y, Mackenzie CF, Orasanu J, Group L (1999) Information acquisition from audio-video-data sources: an experimental study on remote diagnosis. Telemed J 5:139-155

Xiao Y, Moss J, Mackenzie CF, Seagull FJ, Faraj S (2002) Transactive responsibility systems and high reliability teams: a tentative formulation. In: Proceedings human factors and ergonomic society, 46th annual meeting, pp 1428-1432 